\title{
Research biotech patenting 2014
}

\section{Brady Huggett \& Kathryn Paisner}

Our list of patenting activity at top academic centers again has the University of California system in the number one slot (Table 1), with the Wisconsin Alumni Research Foundation and Stanford University trailing. Institut Pasteur sits atop the list of research foundations (Table 2). Figure 1 details the continued increase in overall research patent grants in both the United States and Europe, attributable to offices working through backlogs (Fig. 2), an increase in startup launches and a rising recognition of patent value in research.

\section{COMPETING FINANCIAL INTERESTS}

The authors declare competing financial interests: details are available in the online version of the paper (doi:10.1038/nbt.3288).

Table 1 Top 20 academic centers ranked by number of issued biotech patents, 2010-2014

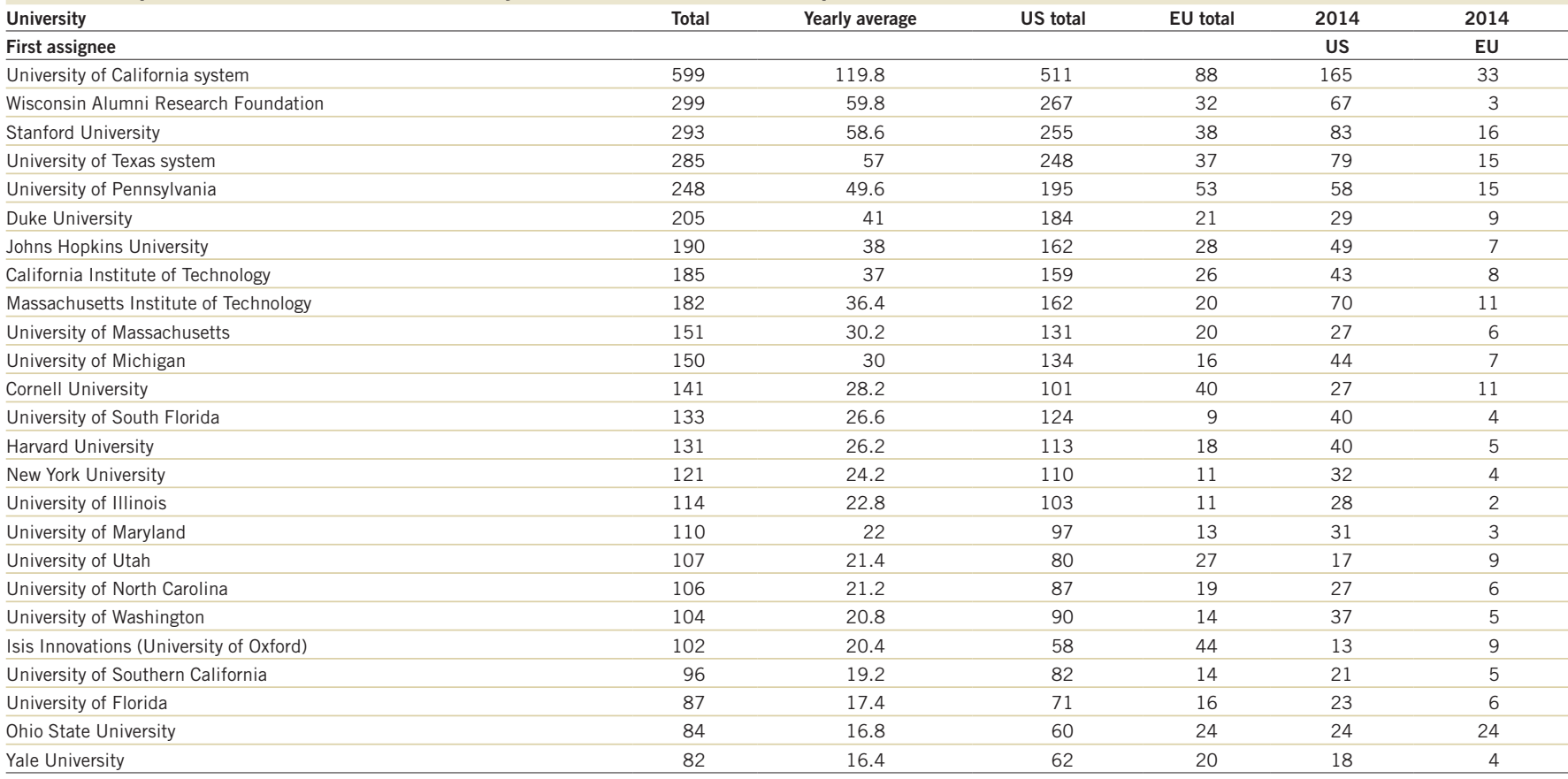

Source: IP Checkups. Query terms: university, college, research foundation, research organization, institute, school, plus our biotech black box searches.

Table 2 Top 5 research institutes ranked by number of issued biotech patents, 2010-2014

\begin{tabular}{|c|c|c|c|c|c|c|}
\hline Institute & Total & Yearly average & US total & EU total & 2014 US & $2014 \mathrm{EU}$ \\
\hline Centre National de la Recherche (CNRS) & 97 & 19.4 & 65 & 32 & 53 & 31 \\
\hline Scripps Research Institute & 80 & 16 & 51 & 29 & 23 & 27 \\
\hline
\end{tabular}

Source: IP Checkups. Query terms: university, college, research foundation, research organization, institute, school, plus our biotech black box searches.

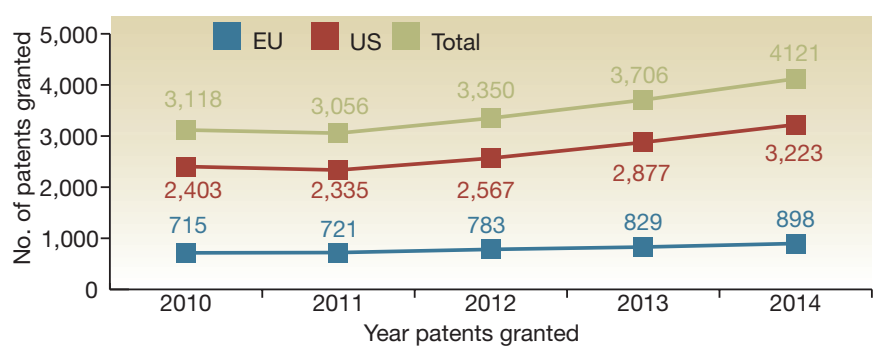

Figure 1 Research biotech patent trends, 2010-2014. Source: IP Checkups.

Brady Huggett is business editor at Nature Biotechnology.

Kathryn Paisner is director of research and analytics at IP Checkups Inc., Berkeley, California, USA.e-mail:kpaisner@ipcheckups.com.

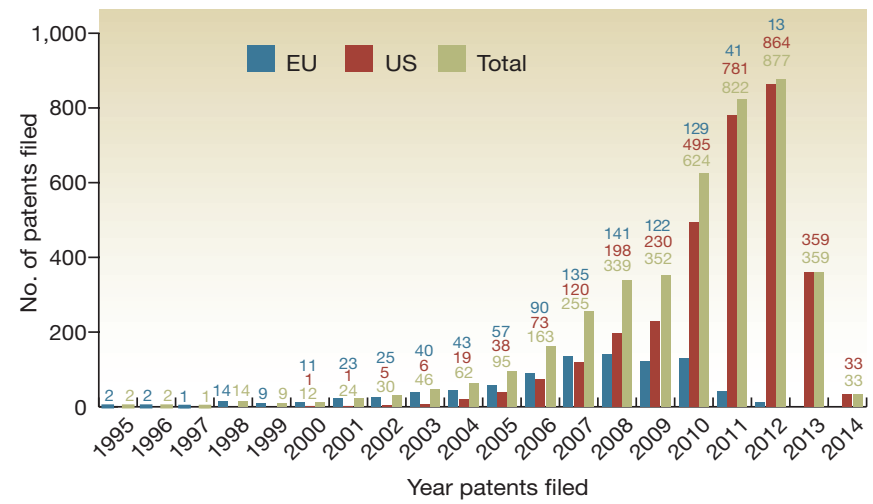

Figure 2 Application dates of research patents issued in 2014. The bulk of biotech patents granted by the US Patent and Trademark Office in 2014 were filed in 2011-2012. For the European Patent Office, the majority were filed in 2007-2008. Source: IP Checkups. 